\title{
Influence of Self-concept and Classroom Environment on the Academic Achievement of Secondary School Students - Exploring the Gender Factor
}

\author{
Samad Thazhe Vadakkayil ${ }^{1 *}$ and Mohd. Moshahid ${ }^{2}$
}

${ }^{1}$ Assistant Professor, Department of Education and Training, Maulana Azad National Urdu University, Gachibowli, Hyderabad, India ${ }^{2} \mathrm{HoD}$, Department of Education and Training, Maulana Azad National Urdu University, Gachibowli, Hyderabad, India

*Corresponding author: samadtvs@gmail.com

\begin{abstract}
The present study was conducted to find out the role of classroom environment and self-concept in the academic achievement of boys and girls in Malayalam medium secondary schools. The sample for the study was collected from various schools of Kozhikode district in the state of Kerala. Sample consists of 300 secondary school students of which 162 are boys and 138 are girls. Different standardized tools were used to measure the classroom environment and parental involvement; and the score of the annual examination was taken as the indicator of academic achievement. Mean standard deviation, $t$-test, $z$-test and stepwise regression analysis were used for analyzing data. The study revealed that both the variables significantly predict the academic achievement of boys and girls. Classroom environment is the highest predictor for both the groups and self-concept follows it in the prediction.
\end{abstract}

Keywords: Self-concept, Classroom Environment, Academic Achievement, Secondary Schools and Gender

Education is considered as the most valuable asset of any individual, society, family and nation. To educate a child means to uplift a society and to develop a nation. Education is the light that shows the way towards all types of success for all. For the students, education opens all the doors to success in personal and social life. People from centuries ago have realized this fact and they have acted accordingly. In the present world, where people can witness the tremendous changes that occur day by day, the importance of obtaining the quality education has become a matter of concern for the students, parents, teachers and the stakeholders. It is a fact that the majority of them are working hard and they leave no stone unturned to achieve their goal in education but it's also a bitter truth that many of them happen to grope in the darkness during their educational journey. At this juncture, it's the need of the time to turn the attention of all the academic community towards ensuring the top class education for all students especially in secondary level. For the students, it's academic achievement that matters. Academic achievement in secondary level usually becomes a yardstick to measure the strength and weakness of students.

Gender has always been a topic of hot discussion with respect to social justice and equal opportunity. It is a fact that some sort of difference is observed between the academic achievement of both male and female students. Earlier, Malathi (1987) reported that intelligence was the only factor that causes gender variations among high achievers. Later, some attributed familial factors like parental aspiration, belief and their socio economic status were reported to be the main factors that cause age and gender differences among high achievers. Janos

\footnotetext{
How to cite this article: Vadakkayil, S.T. and Mohd. Moshahid (2021). Influence of Self-concept and Classroom Environment on the Academic Achievement of Secondary School Students - Exploring the Gender Factor. Educational Quest: An Int. J. Edu. Appl. Soc. Sci., 12(03): 193-198. Source of Support: None; Conflict of Interest: None
} 
et al. (1985) found that boys are superior to girls in literacy rate as it is the current scenario in most of the competitive examinations.

As stated by Conger and Peterson (1984), it is a general assumption that boys and girls show no consistent difference in overall intelligence and their performance in scholastic activities. But some of the recent studies have found an average sex-differences on some specific cognitive abilities, all starting in the early adolescence and continuing to adulthood. These studies concluded that female students outscore males on a variety of measures of verbal ability like creative writing, language production, verbal fluency etc, while male students are far ahead of females on measures of mathematics and spatial ability.

There are many factors to influence the academic achievement of the students. All such factors are related to the students either directly or indirectly. From among these factors, self-concept and classroom environment have a great effect on academic achievement of the students in the secondary stage. Different psychologists have used the term 'self' with variety of suffixes which number to more than one dozen. Terms like selfconcept, self-worth, self-esteem, self-acceptance, and so on have been used as synonyms as they all generally represent the different ideas on what is the thought of people about themselves. Selfconcept is the image of a person that he has about himself. Physical and psychological self-images are included in the self-concept. Children's physical appearance acts as the base for developing their physical self-image whereas their thoughts, feelings and emotions form their psychological self-images.

According to Rogers (1951), self-concept is composed of such elements as the perceptions of one's characteristics and abilities, the percepts and concepts of the self in relation to others and to the environment, the valued qualities which are perceived as associated with experiences and objects; and the goals and ideas which are perceived as having positive or negative valence. Epstein (1989) conceptualizes self-concept in a different way. He puts forth the view that from an attribution perspective, the self-concept is a theory that a person holds about himself as an experiencing, functioning being in interaction with the world.
Though he gives overemphasis on knowledge and beliefs as the foundation for self-concept rather than on values, attitudes, and motivations, Epstein's interesting formulation has paved the way for frequent discussions over self-concept in social psychology.

School is considered as a miniature society and the classroom, a second home. It's in the classroom that we measure the quality and quantity of the cognitive, creative and social life in terms of teacherpupil interaction. It's usually inside the four walls of a classroom that the teacher and the students work together to achieve the predetermined objectives. Education is never considered as an end product of certain activities, but instead it is the numerous processes in which the students take part in various ways. So, it is clear that the classroom environment has a great influence on the academic achievement of the students.

The central assumption in Piaget's (1973) analysis of cognitive change was the belief that development depends upon a continuous interaction between organism and environment, an interaction which involves on the one hand, environmental forces (people, objects, events) acting up on the child and on the other hand, the child acting selectively upon the environment. This notion highlights the importance of the classroom environment in the learning process. The main focus of the learning environment is upon students' and teachers' perceptions of important psychological aspects of the learning environment which pervade school classrooms. It is assumed that having a constructive classroom environment is an intrinsically valuable goal of schooling.

Thelen (1981) described the classroom environment in terms of three components called ALP components. They are Authenticity, Legitimacy and Productivity. Authenticity is pupils' meaningfulness, understanding and pleasant experiences in learning activities. Legitimacy is pupils' effort in solving problems, concern for learning and preparing themselves for the purpose or aim in life. Productivity is pupil's consciousness, effectiveness, potentials and self-learning in productive learning activities. That is the climate of the classroom is essentially the direction and extent to which these constructs operate in varied combinations creating 
a way of life of the class.

Many studies have been conducted to find out the role of self-concept and classroom environment in the academic achievement of boys and girls. Meerah and Mazlan (2017) conducted a study to identify academic self-concept level of Universiti Teknologi MARA (UiTM) Centre of Excellence and the relation of it with athletes' academic achievement. It was a descriptive and correlation research. The population consisted of 75 male PKS athletes from three categories according to their league participation which are the Malaysia Premier League (first team), the Higher Education Institution League (second team) and Selangor League (third team). The tool consisted of two subscales i.e., academic confidence and academic effort. Findings indicated that there is a weak positive correlation between academic selfconcept level and academic achievement. The weak relationship may suggest academic self-concept has less influence on academic achievement.

Stearns (2017) conducted an action research on the relationship between self-concept, teacher expectation and academic achievement of students as an analysis of social-emotional well being and its relation to their classroom performance. Sample of the study included 162 students and 8 teachers from McAlister Intermediate School, an elementary school in Suffield, Connecticut. Piers-Harris Selfconcept Scale (2002) and Collaborative for Academic, Social, and Emotional Learning (CASEL) were used to collect the data. The research concluded that the students with a higher sense of self-concept performed higher in the academic affairs; and that the students in classes where their teachers hold high expectations perform higher academically and report higher sense of self-concept. The study also revealed a disparity between student-perceived expectations held by teachers and teacher-reported expectations which led to conclude that when teachers report having higher academic, social and emotional expectations of their students than their students perceived, their students reported worrying less about assessments and higher rates of not feeling good about their schoolwork than their counterparts. Conversely, when a student reported perceiving higher expectations from their teacher than actually reported by their teacher, students reported higher rates of worrying about tests and feeling positively about their schoolwork.

Kekare (2015) conducted a study to explore the relationship between classroom environment and academic achievement of higher secondary school students. The study was experimental in nature and pre-test post-test equivalent group design was used. A sample of 80 students was taken from various institutions of Aurangabad through simple random sampling technique. Mean, standard deviation and $t$ test were used for statistical procedure. The study found out that the classroom physical environment had significant influence on academic achievement of the students.

Barksdale (2017) examined the relationship between classroom climate and students' academic achievement in middle school. A sequential mixed method study was adopted. Sample of the study was taken purposively from students of $6^{\text {th }}$ to $8^{\text {th }}$ grades in a large suburban school district in southeast Texas. The Learning Environment Inventory (LEI) redeveloped by Fraser, Anderson, and Walberg (1992) was used to collect the data. To get a more in-depth understanding of the potential influence of classroom climate factors on student achievement, a purposeful sample of students in grades 6th -8 th were also interviewed. Quantitative analysis of data discovered that there was not a significant mean difference between classroom climate and students' academic achievement. The qualitative analysis reached at the conclusion that a positive relationship did exist between the two variables.

Ezike (2018) investigated classroom environment and students' academic interest as correlates of achievement in Chemistry of senior secondary students. The study adopted the correlational design. Sample of the study was 208 senior secondary II students selected randomly from ten selected public secondary schools in Ibadan Oyo State, Nigeria. Classroom Environment Students' Questionnaire, Students' Academic Interest Scale and Chemistry Achievement Test were the tools used for data collection. Study found out significant relationship between each of the classroom environment and academic achievement, students' academic interest and achievement in Chemistry. Even though the composite contribution of classroom environment and academic interest was significant, the classroom environment better predicted the academic achievement than students' 
academic interest did.

\section{Objective of the Study}

The study had the following objective:

1. To find out and compare the predictability strength of classroom environment and selfconcept on academic achievement of boys and girls in Malayalam medium secondary schools.

\section{Hypothesis}

Based on the objective, the researcher formulated the following null hypothesis:

1. Classroom environment and self-concept will not be found to be the significant predictors of academic achievement of the boys and girls in Malayalam medium secondary schools; and the two groups will show no significant difference with respect to their predictors or predictability strength.

\section{Methodology}

Survey method was used for the purpose of research. A sample of 300 students was collected using stratified random technique from government and private secondary schools that follow the SCERT syllabus in Kerala. The sample included 162 boys and 138 girls. Classroom Environment Scale standardized by the investigator and Children's Self-Concept Scale (CSCS-AS) standardized by Ahluwalia and Singh (1986) were used to collect the data. Total score obtained by the students in the previous year's annual examination (Std IX) was considered as the academic achievement indicator. Mean, SD, t- test, $\mathrm{z}$ - test, Pearson product moment correlation coefficient (r) and Stepwise multiple regression analysis were used for analysis of the data.

\section{Analysis}

Table 1: Correlation between the predictive variables and the criterion variable

\begin{tabular}{|c|c|c|c|}
\hline \multirow{2}{*}{$\begin{array}{l}\text { Sl. } \\
\text { No. }\end{array}$} & \multirow{2}{*}{$\begin{array}{l}\text { Predictive } \\
\text { variables }\end{array}$} & \multicolumn{2}{|c|}{$\begin{array}{c}\text { Criterion Variable- Academic } \\
\text { Achievement }\end{array}$} \\
\hline & & $\begin{array}{l}\text { Boys sample } \\
(\mathrm{N}=152)\end{array}$ & $\begin{array}{l}\text { Girls sample } \\
(\mathrm{N}=148)\end{array}$ \\
\hline 1 & Self-concept & $0.477^{* *}$ & $0.428^{* *}$ \\
\hline
\end{tabular}

\begin{tabular}{|c|c|c|c|}
\hline 2 & $\begin{array}{l}\text { Classroom } \\
\text { environment }\end{array}$ & $0.583^{* *}$ & $0.577^{* *}$ \\
\hline
\end{tabular}

It is very clear from Table 1 that all the coefficients of correlation of the predictive variables- classroom environment and parental involvement with the criterion variable- academic achievement are positive and significant. The correlation coefficient between academic achievement and classroom environment is found to be 0.58 for boys sample and 0.681 for girls sample. Both of these values of coefficient of correlation ( $\mathrm{r}$ 's) are positive and significant at 0.01 level. This indicates that the students who possess a high level of classroom environment will also obtain high academic achievement. The correlation coefficient between academic achievement and parental involvement is found to be 0.432 for boys sample and 0.497 for girls sample. Both of these values of coefficient of correlation ( $\left.\mathrm{r}^{\prime} \mathrm{s}\right)$ are positive and significant at 0.01 level. This indicates that the students who possess a high level of parental involvement will also obtain the high academic achievement.

Table 2: Stepwise regression analysis between the predictive variables and the criterion variable (Boys sample)

\begin{tabular}{lccll}
\hline $\begin{array}{l}\text { Predictive variables } \\
\text { and academic } \\
\text { achievement }\end{array}$ & df & $\mathbf{R}^{2}$ & $\begin{array}{l}\mathbf{R}^{2}- \\
\text { Change }\end{array}$ & $\begin{array}{l}\text { F- } \\
\text { Change }\end{array}$ \\
\hline $\begin{array}{l}\text { Classroom } \\
\text { environment }\end{array}$ & 160 & 0.339 & 0.339 & $82.229^{* * *}$ \\
$\begin{array}{l}\text { Self-concept } \\
* * *=p<0.001 .\end{array}$ & 159 & 0.394 & 0.054 & $14.207^{* * *}$ \\
\hline
\end{tabular}

From Table 2, it can be clearly observed that the predictive variables self-concept and classroom environment are found to be the significant predictors of the criterion variable i.e., academic achievement for the Malayalam medium boys sample. The predictability strength of the two significant predictive variables on academic achievement of the Malayalam medium boys sample is $39.4 \%$. From among the predictive variables, classroom environment is found to be the more powerful predictor of which the predictability strength is $33.9 \%$ which is significant at 0.001 level. The predictability strength of self-concept is $5.4 \%$.

From Table 3, it can be clearly observed that the 
predictive variables self-concept and classroom environment are found to be the significant predictors of the criterion variable i.e., academic achievement of the Malayalam medium girls sample. The predictability strength of the significant two predictive variables on academic achievement of the Malayalam medium girls sample is $37.8 \%$. From among the predictive variables, classroom environment is found to be more powerful predictor of which the predictability strength is $33.3 \%$ which is significant at 0.001 level. The predictability strength of self-concept is $4.4 \%$.

Table 3: Stepwise regression analysis between the predictive variables and the criterion variable (Girls sample)

\begin{tabular}{lllll}
\hline $\begin{array}{l}\text { Predictive variables and } \\
\text { academic achievement }\end{array}$ & df & $\mathbf{R}^{2}$ & $\begin{array}{l}\mathbf{R}^{2}- \\
\text { Change }\end{array}$ & $\begin{array}{l}\text { Ch- } \\
\text { Change }\end{array}$ \\
\hline Classroom environment & 136 & 0.333 & 0.333 & $67.976^{* * *}$ \\
Self-concept & 135 & 0.378 & 0.044 & \\
\hline
\end{tabular}

$* * *=p<0.001$.

From the analysis of the results presented in Table 4 , it is clear that the shared common variance of self-concept in the academic achievement of boys in Malayalam medium secondary level school is 5.4 when it is 4.4 for the academic achievement of girls in Malayalam medium secondary level school. Results of the z-test conducted to find the difference between these two percentages revealed a z-value of 0.398 which is not significant at any level. So, it can be understood that self-concept plays an equally significant role in determining the academic achievement of boys and girls in Malayalam medium secondary level school.

Table 4: Comparative strength of significant predictors of academic achievement in Boys and Girls sample

\begin{tabular}{|c|c|c|c|}
\hline \multirow{2}{*}{$\begin{array}{l}\text { Predictive } \\
\text { variables and } \\
\text { academic } \\
\text { achievement }\end{array}$} & \multicolumn{3}{|c|}{$\%$ Shared common variance } \\
\hline & $\begin{array}{l}\text { Malayalam } \\
\text { medium boys } \\
\text { sample }\end{array}$ & $\begin{array}{l}\text { Malayalam } \\
\text { medium girls } \\
\text { sample }\end{array}$ & z-value \\
\hline Self-concept & 5.4 & 4.4 & 0.398 \\
\hline $\begin{array}{l}\text { Classroom } \\
\text { environment }\end{array}$ & 33.9 & 33.3 & 0.109 \\
\hline
\end{tabular}

$*=p<0.05$.

The second significant predictor i.e. classroom environment occupies a shared common variance of $33.9 \%$ for the academic achievement of boys in Malayalam medium secondary level school when it is $\mathbf{3 3 . 3}$ for the academic achievement of girls in Malayalam medium secondary level school. Results of the z-test conducted to find the difference between these two percentages revealed a z-value of 0.109 which is not significant at any level. So, it can be understood that the classroom environment plays an equally significant role in determining the academic achievement of boys and girls in Malayalam medium secondary level school.

\section{Findings of the Study}

1. Classroom environment and self-concept are found to be the significant predictors of academic achievement for the boys sample and they occupy the predictability strength of $39.4 \%$.

2. For the boys sample, the classroom environment shares the largest predictable variance which is $33.9 \%$, and self-concept follows it with $5.4 \%$.

3. Classroom environment and self-concept are found to be the significant predictors of academic achievement for the girls sample and they occupy the predictability strength of $37.8 \%$.

4. For the girls sample, the classroom environment shares the largest predictable variance which is $33.3 \%$ and self-concept follows it with $4.4 \%$.

\section{CONCLUSION}

From the above findings, the researcher could arrive at the conclusion that the academic achievement of boys and girls in Malayalam medium secondary school is influenced by their classroom environment and self-concept. From among the two predictors, the classroom environment is found to be the larger one in both the groups. Nevertheless, the prediction of classroom environment for girls' academic achievement is remarkably higher than its prediction for boys' academic achievement. This clearly indicates that the classroom environment provides a good learning atmosphere for both boys and girls.

The present study has revealed that the classroom 
environment plays a dominant role in predicting the academic achievement for both boys and girls. This highlights the necessity of providing the best academic atmosphere in the classrooms. A classroom environment that meets the demands of students and teachers in terms of material facilities and all other supports can definitely motivate the students for obtaining good results in education. When the teachers and students utilize advanced technology and ensure a free and safe learning atmosphere, learning activities will become a joyous journey to conquer all heights of success. It is not only the student as an individual that influences his or her education. There are many factors outside the individual that have great influence on the academic achievement. In the light of the results of the present study, it is suggested that every single teacher, heads of schools, PTA and the government should act vigilantly to ensure that each and every child gets a suitable learning atmosphere in the school.

For the present study has found the self-concept of students as a significant predictor of their academic achievement, it should be given much consideration. Students should be given more and more opportunities to develop better self-concept. Regular sessions ought to be conducted to train them to possess the best self-concept and act accordingly. Such programs will remind them of the need of having a dream and exploring the different means to achieve it. Providing opportunities to interact with the important personalities of the society will help the students in setting the role models and ideal self for them. Briefly, each predictor of academic achievement of boys and girls of Malayalam medium secondary schools needs the attention of the students, teachers, parents and social activists. It is the moral responsibility of all of them to explore vivid ways for supporting the students for achieving their educational objectives and life dreams. To make it successful in the practical field, special attention should be given to the classroom environment and self-concept of the students.

\section{REFERENCES}

Conger, J.J. and Petersen, A.C. 1984. Adolescence and Youth: Psychological Development in a Changing World. ( $3^{\text {rd }}$ ed.) New York: Harper \& Row.

Epstein, J. 1989. Family structures and student motivations; A developmental Perspective. In Research on motivation in Education. 3: Goals and cognitions, Edited by C. Ames and R. Ames. New York: Academic Press.

Ezike, B.U. 2018. Classroom environment and academic interest as correlates of achievement in Senior Secondary School Chemistry in Ibadan South West Local Government Area, Oyo State, Nigeria. Global Journal of Educational Research, 17: 61-71.

Janos, P.M., Fung, H.C. and Robinson, N.M. 1985. Self-concept, self-esteem, and peer relations among gifted children who feel "different". Gifted Child Quarterly, 29(2): 78-82.

Kekare, S.H. 2015. Classroom physical environment and academic achievement of students. The International Journal of Indian Psychology, 2(3).

Piaget, J. 1973. The psychology of intelligence. Totowa, NJ: Littlefield \& Adams.

Rogers, C.R. 1951. Client-centered therapy: its current practice implication and theory. Boston: Houghton Miffin.

Stearns, K.E. 2017. Unpublished certificate of advanced study thesis, Sacred Heart University, Fairfield, CT. Retrieved from http://digitalcommons.sacredheart.edu/edl/19.

Thelen, H.A. 1981. The classroom society, London: Croom Helm Limited. 